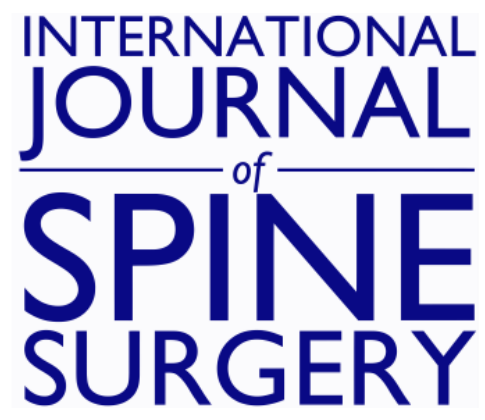

\title{
Multi-center, Prospective, Randomized, Controlled Investigational Device Exemption Clinical Trial Comparing Mobi-C Cervical Artificial Disc to Anterior Discectomy and Fusion in the Treatment of Symptomatic Degenerative Disc Disease in the Cervical Spine
}

Michael S. Hisey, Hyun W. Bae, Reginald Davis, Steven Gaede, Greg Hoffman, Kee Kim, Pierce D. Nunley, Daniel Peterson, Ralph Rashbaum and John Stokes

Int J Spine Surg 2014, 8 ()

doi: https://doi.org/10.14444/1007

http://ijssurgery.com/content/8/7

This information is current as of April 26, 2023.

Email Alerts Receive free email-alerts when new articles cite this article. Sign up at: http://ijssurgery.com/alerts 


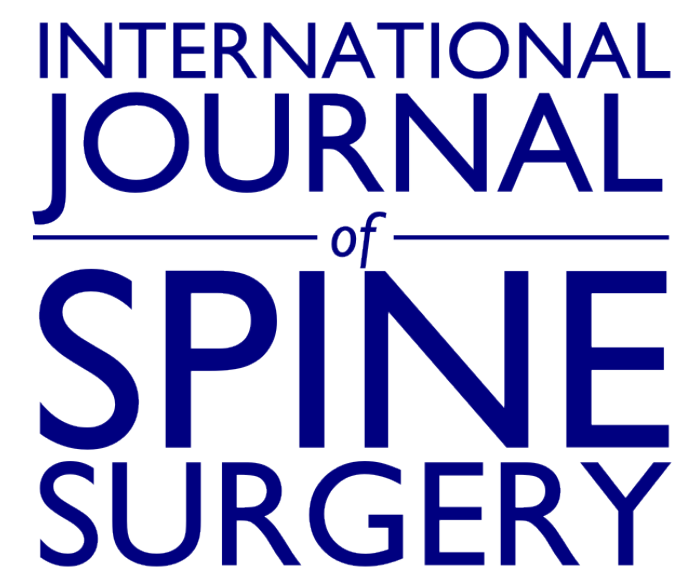

This article generously published free of charge by the International Society for the Advancement of Spine Surgery.

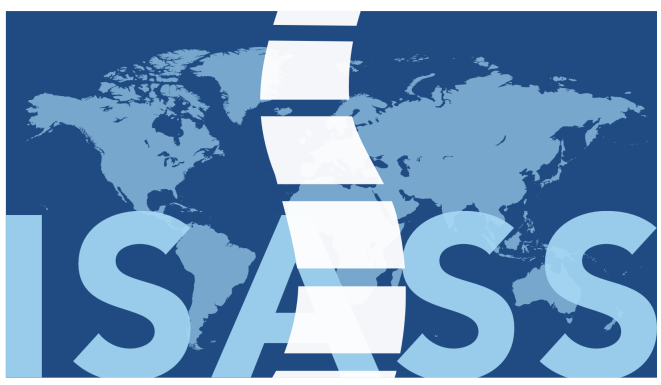

INTERNATIONAL SOCIETY for the ADVANCEMENT of SPINE SURGERY 


\section{Multi-center, Prospective, Randomized, Controlled}

Investigational Device Exemption Clinical Trial Comparing Mobi-C Cervical Artificial Disc to Anterior Discectomy and Fusion in the Treatment of Symptomatic Degenerative Disc Disease in the Cervical Spine

Michael S. Hisey, MD ${ }^{1}$ Hyun W. Bae, MD, ${ }^{2}$ Reginald Davis, $M D,{ }^{3}$ Steven Gaede, $M D,{ }^{4}$ Greg Hoffman, MD, ${ }^{5}$ Kee Kim, MD, ${ }^{6}$ Pierce D. Nunley, MD, ${ }^{7}$ Daniel Peterson, $M D,{ }^{8}$ Ralph Rashbaum, $M D,{ }^{9}$ John Stokes, $M D^{8}$

${ }^{1}$ Texas Back Institute, Denton, TX; ${ }^{2}$ The Spine Institute at St. John's Health Center, Santa Monica, CA; ${ }^{3}$ GBMC Healthcare Greater Baltimore Neurosurgical Associates, Baltimore MD; ${ }^{4}$ Oklahoma Spine \& Brain Institute, Tulsa, OK, ${ }^{5}$ Orthopedic North East, Fort Wayne, IN; ${ }^{6}$ University of California Davis Medical Center, Sacramento, CA, ${ }^{7}$ Spine Institute of Louisiana, Shreveport, LA;

${ }^{8}$ Neurological Specialists of Austin, Austin, TX; ${ }^{9}$ Texas Back Institute, Plano, TX

\section{Abstract}

\section{Background}

Anterior cervical discectomy and fusion (ACDF) is the gold standard for treating symptomatic cervical disc degeneration. Cervical total disc replacements (TDRs) have emerged as an alternative for some patients. The purpose of this study was to evaluate the safety and effectiveness of a new TDR device compared with ACDF for treating singlelevel cervical disc degeneration.

\section{Methods}

This was a prospective, randomized, controlled, multicenter Food and Drug Administration (FDA) regulated Investigational Device Exemption (IDE) study. A total of 245 patients were treated (164 TDR: 81 ACDF). The primary outcome measure was overall success based on improvement in Neck Disability Index (NDI), no subsequent surgical interventions, and no adverse events (AEs) classified as major complications. 
Secondary outcome measures included SF-12, visual analog scale (VAS) assessing neck and arm pain, patient satisfaction, radiographic range of motion, and adjacent level degeneration. Patients were evaluated preoperatively and postoperatively at 6 weeks, 3, 6, 12,18 , and 24 months. The hypothesis was that the TDR success rate was non-inferior to ACDF at 24 months.

\section{Results}

Overall success rates were $73.6 \%$ for TDR and $65.3 \%$ for ACDF, confirming noninferiority $(p<0.0025)$. TDR demonstrated earlier improvements with significant differences in NDI scores at 6 weeks and 3 months, and VAS neck pain and SF-12 PCS scores at 6 weeks $(p<0.05)$. Operative level range of motion in the TDR group was maintained throughout follow-up. Radiographic evidence of inferior adjacent segment degeneration was significantly greater with ACDF at 12 and 24 months $(p<0.05)$. AE rates were similar.

\section{Conclusions}

Mobi-C TDR is a safe and effective treatment for single-level disc degeneration, producing outcomes similar to ACDF with less adjacent segment degeneration. Level of Evidence: Level I.

Clinical relevance: This study adds to the literature supporting cervical TDR as a viable option to ACDF in appropriately selected patients with disc degeneration.

keywords: clinical outcome, randomized study, anterior cervical fusion, Cervical Spine, total disc replacement Volume 8 Article 7 doi: 10.14444/1007

\section{Introduction}

Cervical disc degeneration is known to be a primary cause of neck pain and neurologic symptoms and can cause significant morbidity. ${ }^{1}$ Degeneration can be related to radiculopathy or myelopathy due to compression of spinal nerves and/or spinal cord. ${ }^{2}$ Decompressive surgery has been shown to be effective at reducing symptoms. Anterior cervical discectomy and fusion (ACDF) has been established as the primary surgical technique to decompress the spinal cord and nerve roots. ${ }^{3}$ There are three main goals of ACDF: decompression of the neural element, maintenance of lordosis, and stabilization of the motion segment. ${ }^{4}$ Typically, bone graft or a cage in conjunction with a rigid anterior plate are implanted to maintain or restore disc space integrity, provide stability, and facilitate fusion. With ACDF good clinical outcomes are generally achieved in a high percentage of patients. ${ }^{5,6} 7$ In particular, procedures which use allograft bone and an anterior plate produce overall positive patient outcomes, reduce post-operative bracing, and reduce complications associated with graft resorption, migration, and subsidence. ${ }^{8}$ Long term reduction in symptoms associated with degenerative disc disease (DDD) has led to ACDF being generally accepted as the gold standard of treatment for indicated patients. ${ }^{9}$ Despite benefits of ACDF, it is not without complications. ACDF with allograft bone and anterior plating has been associated with complications such as screw back out, plate fracture, dysphagia, adjacent segment degeneration, and pseudoarthrosis. ${ }^{6,10,11}$ 
Artificial cervical discs have been used since the 1990's. ${ }^{12,13}$ Total disc replacement (TDR), as an alternative to ACDF in the treatment of symptomatic cervical DDD, is becoming increasingly common and potentially provides some advantages over ACDF. Not only does TDR provide the same anterior neural decompression and maintenance of disc space as $\mathrm{ACDF}^{14}$, it can also preserve segmental mobility. ${ }^{15}$ Recently several Food and Drug Administration (FDA) Investigational Device Exemption (IDE) trials have demonstrated that TDR is at least as safe and effective as ACDF for of single-level symptomatic cervical DDD. ${ }^{16,17,18}$ Furthermore, these studies found that TDR preserves segmental mobility and these patients tended to have better clinical outcomes earlier after surgery and maintained good quality clinical outcomes at 2 years postoperatively. Additionally, longer term studies found that TDR provides excellent clinical outcomes 5 to 8 years post-operatively. ${ }^{19,20,21}$ Good clinical outcomes for cervical TDRs have also been demonstrated in European studies. ${ }^{22,23}$

One potential advantages of TDR over fusion was the reduction of adjacent segment degeneration (ASD). Reports on the clinical impact of ASD have been mixed, with some variation attributable to there being radiographic findings of ASD not associated with clinical symptoms. Nunley et al. reported a rate of ASD in TDR patients of $3.1 \%$ per year. ${ }^{24}$ Although not a primary part of their study, comparison to ACDF found no significant difference in the occurrence rate. Other studies have found an increased rate of ASD in fusion patients based on either radiographic findings ${ }^{25}$ or a trend toward a higher rate of re-operation at the adjacent segment to treat new symptoms. ${ }^{26}$

The Mobi-C Artificial Cervical Disc (LDR Medical; Troyes, France) was introduced outside the United States in November 2004. A European non-comparative, prospective, multi-center study evaluated the safety and efficacy of this device in the treatment of cervical DDD in 335 patients. This study found statistically significant improvements in clinical outcomes and pain scores compared to baseline at 24 months post-operatively. ${ }^{22,}$ 23

The current study reports the 2-year follow-up results of a prospective, randomized, concurrently controlled, multicenter clinical trial to determine the safety and efficacy of TDR with the Mobi-C Artificial Cervical Disc versus ACDF at a single level for treatment of symptomatic cervical DDD. The hypothesis was that clinical outcomes of patients treated with TDR would not be inferior to outcomes of patients with the control treatment at 24 months.

\section{Material and Methods}

\section{Study design}

A non-inferiority study design with a 2:1 randomization (TDR: control) was prospectively planned for this FDA-regulated IDE study. A 5\% advantage was hypothesized based on pilot study data. A projected $75 \%$ success rate for control and $80 \%$ success rate for TDR with respect to the primary endpoint was used along with the 2:1 randomization scheme. A total sample size of 222 randomized cases (148 TDR vs. 74 control) was determined to meet statistical power requirements to test for non-inferiority with the one-sided $95 \%$ lower confidence bound on the difference exceeding $-10 \%$. An additional 10\% was added 
to the 222 to account for patients that may be lost to follow-up, bringing the total sample size to 245. The population discussed in this report, with the exception of peri-operative data and adverse events, is the Intent-To-Treat population (ITT), which consisted of all subjects who were randomized and received study surgery. The ITT population consisted of 164 TDR patients and 81 control patients. Peri-operative data is presented for the Safety Population, which included all patients in the ITT population as well as the 15 nonrandomized training cases.

All principle investigators were trained on the surgical technique for the study device as part of this IDE; which did consist of a separate two-level arm ran concurrently and using the same investigational device. ${ }^{27}$ Each site was allotted one training case with the investigational device; 15 sites performed training cases for a one level indication, all others performed training with a two level case. This resulted in 15 additional TDR patients (the non-randomized training cases) in the one level IDE.

The primary endpoint of the investigation was a composite measure assessed at 24 months. To be considered a success a patient had to be successful in each of the following three measures: 1) NDI success, a 30 point improvement in score if baseline NDI score was greater than or equal to 60 , or a $50 \%$ of baseline score improvement in NDI score if baseline NDI scores were less than 60,2 ) No device related subsequent surgical intervention at the index level (defined as removal, revision, supplemental fixation, or reoperation), and 3) No study defined major complications which were defined as radiographic failure, neurologic deterioration, and adverse events determined to be major complications by an independent Clinical Events Committee (CEC). In the TDR group, radiographic failure deemed to be a major complication was defined as: Spontaneous fusion of the treatment level with radiographic evidence of bridging bone across the treated disc space and less than $2^{\circ}$ of angular motion from flexion to extension. In the ACDF group, radiographic failure deemed to be a major complication was defined as: Pseudoarthrosis at the treated level demonstrated by greater than or equal to $2^{\circ}$ of angular motion on flexion to extension, or radiolucent lines at greater than $50 \%$ of the graft vertebral interfaces, or absence of bridging bone across the graft vertebral interfaces. This composite measure of success was used to determine overall success rates for both groups.

Study surgeries were performed for the 245 patients in the ITT population and the 15 nonrandomized training cases that received the investigational device between April 2006 and March 2008. The study was conducted by 25 principal investigators at 23 sites. All patients were randomized to groups by an Interactive Voice Randomization System (IVRS). The investigator or study coordinator called the IVRS after the pre-operative inclusion/exclusion checklist confirmed eligibility and informed consent form was signed. Patients were assigned to the TDR or control group by IVRS according to a stratified randomization schedule (by baseline Neck Disability Index (NDI) score) with institutional balancing. Due to the fact that the implant was evident to the surgeon, blinding the physician to treatment was not possible. Patients remained blinded to the treatment group assignment until after surgery had been performed to minimize the potential for disproportionate patient dropouts. 
The primary study hypothesis tested TDR non-inferiority against ACDF using a 10\% margin with respect to patient success at 24 months. Additional secondary endpoints were: neck and arm pain (VAS), neck disability (NDI), patient satisfaction, quality of life (SF-12), and radiographic outcomes (adjacent segment degeneration, range of motion (ROM), significant radiolucency, and displacement or migration). Further measurements of interest were analyzed and included operative time, blood loss, duration of hospitalization, and time to return to work. Patients were evaluated pre-operatively and post-operatively at 6 weeks, and 3, 6, 12, 18, and 24 months. Patients completed the following questionnaires: NDI, VAS for neck and arm pain, SF-12 (Medical Outcomes Study 12-Item Short Form Health Survey), Functional Outcome Swallowing Scale (FOSS) for dysphagia, and patient satisfaction. Neurological examinations were conducted and classified according to a pre-determined algorithm. Three neurological tests were performed including motor, reflex, and sensory assessments. Diminished neurological status was defined as a decrease in two points when compared to baseline status in any of the treated level motor or reflex assessments or a decrease of one point when compared to baseline of the treated level sensory tests. Any new or worsening signs were reported as an adverse event (AE). A baseline for Nurick's classification of cervical spondylotic myelopathy (CSM) was established pre-operatively.

\section{Patient selection criteria}

The primary inclusion criteria were: diagnosis of DDD with radiculopathy or myeloradiculopathy from $\mathrm{C} 3$ to $\mathrm{C} 7$ at one level without prior cervical fusion. DDD was defined as discogenic neck and/or arm pain with degeneration of the disc confirmed by patient history and by radiographic study. Patients were to have been unresponsive to non-operative treatment for at least six weeks from symptom onset or had progressive symptoms or signs of nerve root/spinal cord compression despite continued nonoperative treatment (i.e. acute presentation). See Table 1 for detailed selection criteria.

Table 1. Study Inclusion and Exclusion Criteria

Inclusion criteria 
- Age 18-69 years

- Symptomatic cervical degenerative disc disease in only one level between C3-C7 with:

- Neck and/or arm pain and/or

- Decreased muscle strength and/or

- Abnormal sensation and/or abnormal reflexes

- Deficit confirmed by imaging (CT, MRI, or X-ray)

- NDI score of $\geq 30$

- Unresponsive to non-operative, conservative treatment for at least 6 weeks or presence of progressive symptoms or signs of nerve root/spinal cord compression despite continued non-operative treatment

- No prior surgery at the operative level and no prior cervical fusion procedure at any level

- Physically and mentally able and willing to comply with the protocol

- Signed informed consent

- Willingness to discontinue all use of non-steroidal anti-inflammatory drugs (NSAIDs) from one week before surgery until 3 months after surgery 
- More than one vertebral level requiring treatment/immobile level between $\mathrm{C} 1$ and $\mathrm{C} 7$ from any cause

- Any prior spine surgery at operative level of any prior cervical fusion at any level

- Disc height less than $3 \mathrm{~mm}$

- T-score less than -1.5 (osteoporosis evaluation)

- Paget's disease, osteomalacia, or any other metabolic bone disease other than osteoporosis

- Active systemic infection of surgical site or history of or anticipated treatment for systemic infection including HIV/Hepatitis C

- Active malignancy: a history of any invasive malignancy (except non-melanoma skin cancer), unless treated with curative intent and there had been no clinical signs or symptoms of the malignancy $>5$ years

- Marked cervical instability on resting lateral or flexion-extension radiographs

- Known allergy to cobalt, chromium, molybdenum, or polyethylene

- Segmental angulation of greater than $11^{\circ}$ at treatment or adjacent levels

- Rheumatoid arthritis, lupus, or other autoimmune disease

- Any diseases or conditions that would preclude accurate clinical evaluation

- Daily, high-dose oral and/or inhaled steroids or a history of chronic use of high dose steroids

- $\mathrm{BMI}>40$

- Use of any other investigational drug or medical device within 30 days prior to surgery

- Pending personal litigation relating to spinal injury (worker's compensation not included)

- Smoking more than one pack of cigarettes per day

- Reported to have mental illness or belonged to a vulnerable population

\section{Device description}

The TDR used in this study was the Mobi-C Cervical Artificial Disc (LDR Medical, Troyes, France). This prosthesis is a three component, mobile-bearing device comprised of two titanium plasma-sprayed and hydroxyapatite (HA) coated cobalt chromium alloy endplates and an ultra-high molecular weight polyethylene (UHMWPE) mobile insert. 
The superior endplate incorporates a convex shape to match the natural cervical anatomy, and both the superior and inferior endplates feature low-profile, inclined teeth along the lateral edges to provide initial stability (Figure 1). The shape of the device and inclined teeth were designed to facilitate a bone sparing surgical technique. The device is available in several footprints and a range of heights to satisfy individual anatomical requirements. The device allows five independent degrees of freedom, two translational and three rotational (Figure 1).

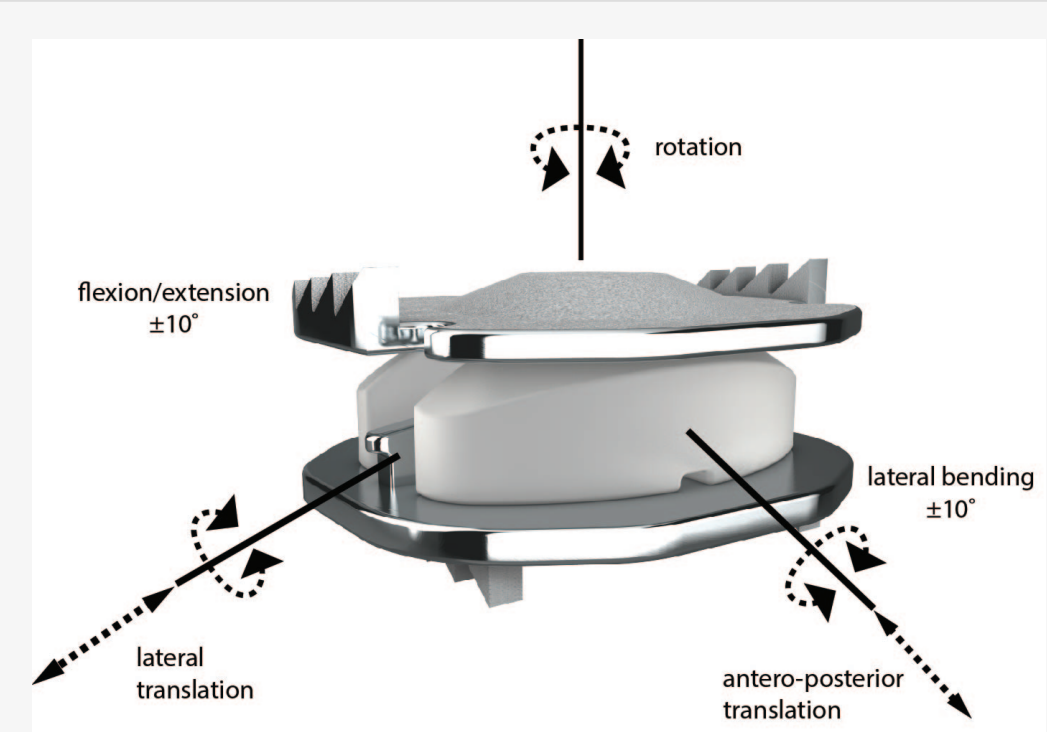

Fig. 1. Mobi-C Artificial Cervical Disc (LDR Medical; Troyes, France). Allows for five independent degrees of freedom.

\section{Surgical approach}

For both treatment groups, the patient was positioned physiologically neutral to avoid hyperextension. This position was maintained throughout surgery and head rotation was minimized. A standard Smith Robinson approach was used to access the anterior cervical spine. A discectomy was performed in which the disc and the osteophytes were removed and the involved neural structures were decompressed.

\section{ACDF Procedure}

For the control group, a standard ACDF technique was used. The disc space was filled with corticocancellous allograft bone and an anterior cervical plate was placed over the graft and secured with screws to the vertebrae according to the manufacturer's published surgical technique. Anterior cervical plate selection was limited to the SLIM-LOC ${ }^{\text {TM }}$ Anterior Cervical Plate System (Depuy Spine; Raynham, MA) and the Sofamor Danek ATLANTIS $^{\text {TM }}$ or ATLANTIS ${ }^{\text {TM }}$ VISION Anterior Cervical Plate Systems (Medtronic; Memphis, TN).

\section{TDR Procedure}

In the TDR group, following the discectomy, the disc space was distracted in parallel using a vertebral distractor. With normal disc height restored, distraction was maintained with a Caspar distractor. The cartilaginous endplates were removed to expose the underlying bone but no endplate shaping was performed. Using fluoroscopy and the trial 
instruments provided, the appropriate Mobi-C footprint and height were selected. The assembled prosthesis was then impacted into the prepared disc space using a self-retaining inserter. An adjustable stop allowed precise modification of the implant's anteroposterior (AP) position. Once final position was obtained, the distraction was released and slight compression was applied via the Caspar distractor to facilitate seating of the implant teeth into the vertebrae. AP and lateral fluoroscopy was used to confirm final implant position (Figure 2).

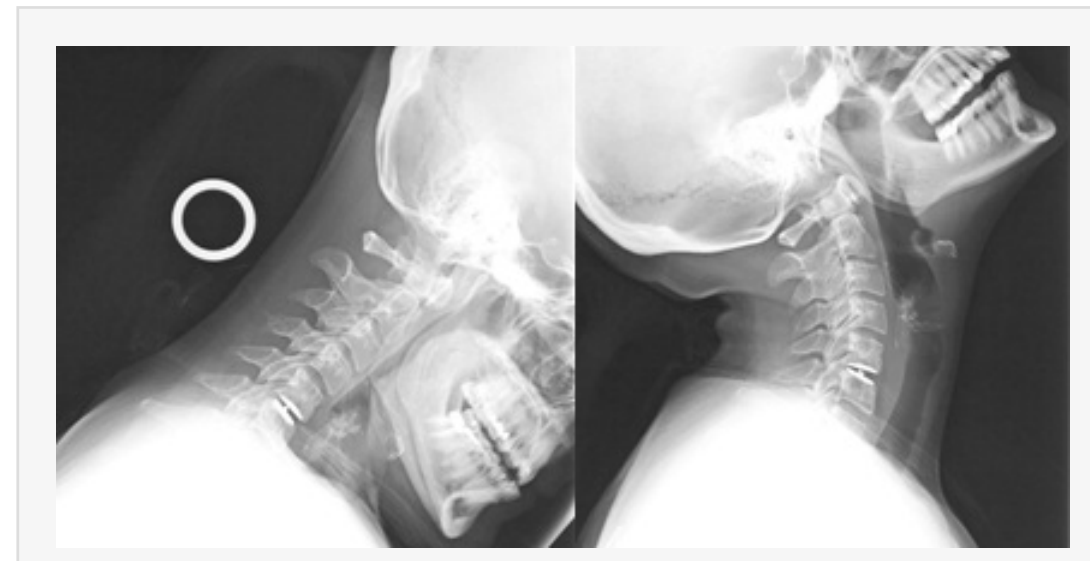

Fig. 2. TDR device in proper placement. Lateral flexion and extension $\mathrm{x}$-rays of the TDR at 24 months.

\section{Post-operative care}

Post-operative care was left to surgeon discretion. Antibiotic coverage and rehabilitation were continued in accordance with the surgeon's standard procedures. In order to ensure consistent treatment between the TDR and ACDF groups and to avoid any potential handicapping of the ACDF group, patients were instructed not to use NSAIDS for one week prior to surgery and the treating physician was instructed not to prescribe NSAIDs prophylactically for 3 months following surgery. However, physicians were allowed to prescribe NSAIDs to treat diagnosed incidence of heterotopic ossification (HO).

\section{Radiographic Assessments}

The following X-ray views were obtained pre-operatively and at all follow-up visits: neutral AP, neutral lateral, flexion-extension, and left-right bending. For consistency, an independent provider of radiographic assessments performed the radiographic analysis for this study. All assessments were made according to a pre-determined radiographic analysis protocol. This protocol specified that measurements of disc angle, angular motion, translational motion, anterior disc height, and change in disc height were quantitatively determined using validated QMA software (Medical Metrics Inc., Houston TX). ${ }^{28,29}$ Specific vertebrae were outlined and the 4 corners of the vertebral centrum specified. Using the radiograph made with the spine in the neutral position, anatomic landmarks were selected. Using an algorithm based on gray-scale correlation, the software found the specific vertebrae in each of the images (flexion, extension, and neutral) and calculated the geometric coordinates of each anatomic landmark on the vertebra. This process was repeated for each vertebra and intervertebral motion was calculated based on the geometric coordinates. 
All other assessments such as bony bridging, radiolucency, fusion status, device condition, device migration, device subsidence, device position, and adjacent level degeneration were made by qualified independent radiologists affiliated with Medical Metrics Inc. Subsidence was defined as greater than $3 \mathrm{~mm}$ cranial or caudal motion of the device (or device component) perpendicular to the vertebral endplates. Migration was defined as greater than $3 \mathrm{~mm}$ anterior or posterior motion of the device (or device component) parallel to the vertebral endplates. Significant radiolucency was defined as more than $50 \%$ coverage of radiolucent lines along device/endplate interface.

Radiographic success was defined as the absence of fusion of the treated level in the TDR, requiring $2^{\circ}$ or more of angular motion from flexion to extension or no radiographic evidence of bridging bone across the treated disc space. In the ACDF group radiographic successful fusion at the treated level was defined as evidence of bridging bone across the disc space, less than $2^{\circ}$ angular motion from flexion to extension, and less than $50 \%$ radiolucent lines at graft vertebral endplate interfaces. Adjacent segment degeneration was assessed at baseline and at the 12 and 24-month visits. Levels both superior to and inferior to the treated level were scored on the Kellgren-Lawrence scale of disc degeneration $^{30,31}$ at baseline, 12, and 24 months. Each disc was classified as having none (0), minimal (1), definite (2), moderate (3), or severe (4) degeneration and was given the corresponding numerical score. To assess adjacent level degeneration over the course of the study, change in disc degeneration score from the baseline score of both adjacent levels was calculated at 12 and 24 months and any negative change (increase in score) was classified as adjacent level degeneration.

\section{Statistical analysis}

The analysis goal was to establish non-inferiority using the composite success measure. Non-inferiority was tested using an exact $95 \%$ one-tailed confidence bound for the study-control success rate; if a 10\% offset could be ruled out, then superiority was to be tested. A closed testing procedure was used to allow for superiority to be tested in the event that non-inferiority was established for the primary effectiveness endpoint. VAS, NDI, and SF-12 results are described using summary statistics (N, mean, median, standard deviation, inter-quartile range, minimum, and maximum) and compared across treatment groups using two sample t-test.

\section{Results}

\section{Patient accountability and demographics}

Demographics characteristics of the ITT population are shown in Table 2. The ITT population consists of 164 patients in the investigational group and 81 patients in the control group. The 24-month follow-up rate (defined as subjects presenting at 24 months with a composite study success value) $94.3 \%$ in the TDR group and $92.0 \%$ in the ACDF group. The groups were well balanced in terms of demographic characteristics with no significant differences between groups.

Table 2. Patient Demographics - intent to treat population.

Patient Group 


\begin{tabular}{|c|c|c|c|}
\hline Variable & TDR & ACDF & $p$ value \\
\hline Age (years) & & & $0.5657^{*}$ \\
\hline $\mathrm{N}$ & 164 & 81 & \\
\hline Mean (SD) & $43.3(9.2)$ & $44.0(8.2)$ & \\
\hline Gender n (\%) & & & $0.6843 * *$ \\
\hline Male & $78(47.6 \%)$ & $36(44.4 \%)$ & \\
\hline Female & $86(52.4 \%)$ & $45(55.6 \%)$ & \\
\hline Ethnicity n (\%) & & & $0.6667^{* *}$ \\
\hline Hispanic or Latino & $3(1.8 \%)$ & $2(2.5 \%)$ & \\
\hline Not Hispanic or Latino & $161(98.2 \%)$ & $79(97.5 \%)$ & \\
\hline Race n (\%) & & & $0.0710^{* *}$ \\
\hline American Indian & $2(1.2 \%)$ & $1(1.2 \%)$ & \\
\hline Caucasian & $152(92.7 \%)$ & $69(85.2 \%)$ & \\
\hline Asian & $3(1.8 \%)$ & $1(1.2 \%)$ & \\
\hline Black or African American & $4(2.4 \%)$ & $10(12.3 \%)$ & \\
\hline Native Hawaiian/Other Pacific Islander & $1(0.6 \%)$ & 0 & \\
\hline Other & $2(1.2 \%)$ & 0 & \\
\hline BMI & & & $0.8460 *$ \\
\hline Mean (SD) & $27.3(4.4)$ & $27.4(4.2)$ & \\
\hline Work Status n (\%) & & & $0.3264 * *$ \\
\hline Being able to work & $108(65.9 \%)$ & $46(56.8 \%)$ & \\
\hline Not being able to work & $37(22.6 \%)$ & $22(27.2 \%)$ & \\
\hline $\mathrm{N} / \mathrm{A}$ & $19(11.6 \%)$ & $13(16.0 \%)$ & \\
\hline Driving Status n (\%) & & & $0.5035^{* *}$ \\
\hline Being able to drive & $155(94.5 \%)$ & $79(97.5 \%)$ & \\
\hline Not being able to drive & $8(4.9 \%)$ & $2(2.5 \%)$ & \\
\hline N/A & $1(0.6 \%)$ & 0 & \\
\hline NDI Mean (SD) & $54.0(14.0)$ & $54.2(14.6)$ & $0.9290 *$ \\
\hline VAS Neck Pain Mean (SD) & $70.8(22.4)$ & $70.1(21.5)$ & $0.8354 *$ \\
\hline VAS Left Arm Pain Mean (SD) & $46.7(36.5)$ & $55.3(37.3)$ & $0.0839 *$ \\
\hline VAS Right Arm Pain Mean (SD) & $41.0(36.2)$ & $34.8(35.6)$ & $0.2104 *$ \\
\hline SF-12 PCS Mean (SD) & $32.5(5.91)$ & $33.8(6.36)$ & $0.1055^{*}$ \\
\hline SF-12 MCS Mean (SD) & $42.1(13.1)$ & $42.2(10.4)$ & $0.9792 *$ \\
\hline
\end{tabular}


* using unpaired t-test to compare across treatment groups

** using Fisher exact test to compare. Fisher exact p-value calculation is based on

Caucasian vs. non-Caucasian subjects. Fisher exact p-value is based on 'being able to' vs.

'not being able to'

\section{Overall Success at Primary Endpoint}

The primary composite endpoint assessed individual patient success as demonstrated by functional improvement (NDI), no need for subsequent surgical intervention (removal, revision, supplemental fixation, reoperation), and the absence of study defined major complications including neurologic deterioration, CEC-assessed adverse events, and radiographic failure. The composite success rate for TDR patients was $73.7 \%$ at month 24, compared to $65.3 \%$ success rate for ACDF (Figure 3). The composite endpoint results establish TDR non-inferiority for the primary endpoint $(\mathrm{p}=0.0021)$. Additionally, TDR patients tended to achieve success earlier than ACDF patients. At 6 month time point, $75.0 \%$ of TDR patients achieved composite success, compared with $41.4 \%$ of ACDF patients (Figure 4). 


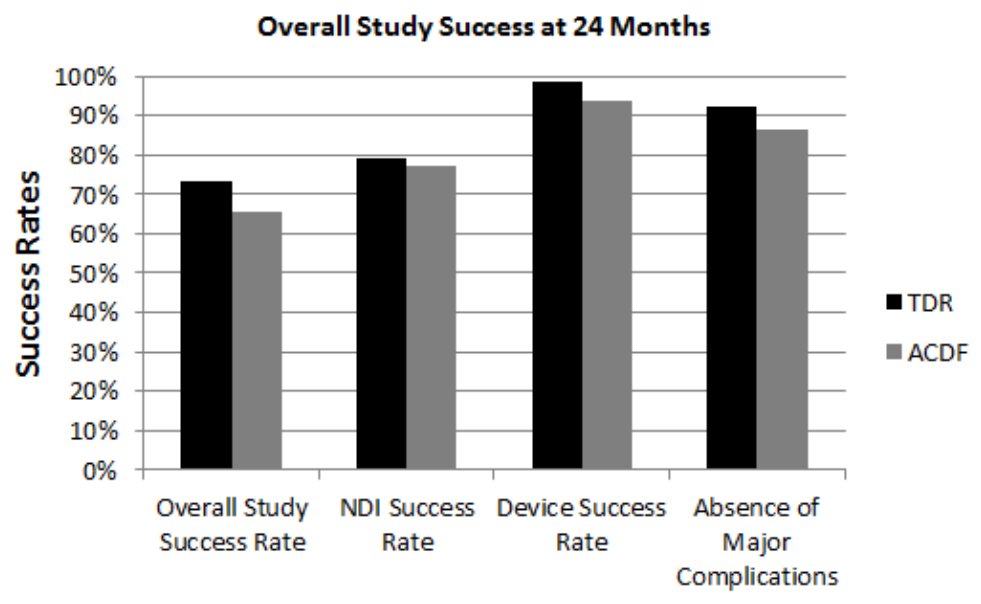

Fig. 3. Overall Study Success at 24 Months. Bar graph showing over all clinical success rate at 24 months. Also shown are the success rates at 24 months of the components of the composite endpoint: NDI success rate, Device success rate (no need for subsequent surgeries, and the percentage of patients who had no major complications.

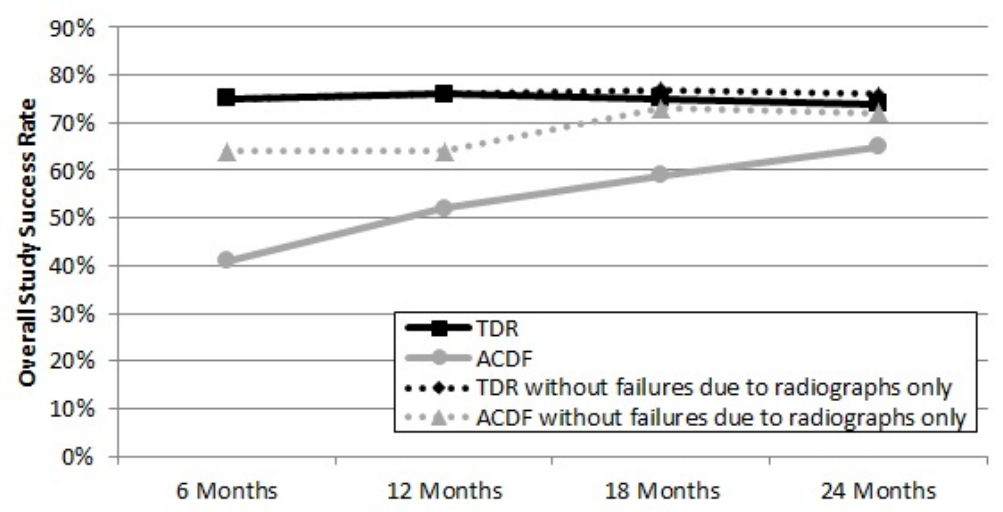

Fig. 4. Overall Study Success Rates by Time point. Success rates are shown for both TDR group and ACDF group both with and without failures due only to radiographic major complications. Non-inferiority is demonstrated at each time point for both TDR compared to ACDF in both cases.

\section{Overall Success at Primary Endpoint - Effect of Radiographic Major Complications}

To analyze the effect of radiographic complications on the success rates of TDR and ACDF at each follow-up time point, a variation to the primary endpoint analysis was prospectively planned. These results are also shown in Figure 4. For this analysis, all patients that were failures due only to radiographic failure were treated as a study success. The composite success rates in this analysis were $76.3 \%$ for the TDR group and $72.0 \%$ for the ACDF group. This analysis led to an increase in ACDF success, resulting in smaller differences between TDR and ACDF overall success, however overall success 
still favors TDR (8.4\% difference with radiographic failures and $4.3 \%$ difference between groups without radiographic failures). This result further confirms non-inferiority of TDR to ACDF even when radiographic only failures are excluded $(p=0.0094)$.

Additionally, in this analysis TDR patients achieved success sooner than patients in the ACDF group. Even excluding those patients who failed the study only due to defined radiographic failure, only $64.3 \%$ of ACDF patients were deemed an overall study success at 6 months and $63.8 \%$ at 12 months. By 18 months the success rate of ACDF increased to $72.7 \%$ and remained roughly the same at 24 months $(72.0 \%)$. This pattern is contrasted in the TDR group where $75.0 \%$ of patients achieved success by 6 months and the success rate remained relatively constant with $76.3 \%$ success at 12 months, $76.7 \%$ at 18 months, and $76.3 \%$ at 24 months.

\section{Surgical data}

Peri-operative data is shown in Table 3 for the safety population. The mean and median blood loss and length of hospital stay were similar between treatment groups. The operative time was slightly higher in the TDR group, with a mean of 1.5 hours, compared with 1.3 hours for ACDF.

Table 3. Perioperative Data - Safety Population

\begin{tabular}{|c|c|c|c|}
\hline \multirow[b]{2}{*}{ Variable } & \multicolumn{2}{|c|}{ Patient Group } & \multirow[b]{2}{*}{$p$ value $\mathrm{e}^{* *}$} \\
\hline & TDR & ACDF & \\
\hline Duration of Hospitalization* & & & 0.9829 \\
\hline $\mathrm{N}$ & 179 & 81 & \\
\hline Mean (SD) & $2.1(0.52)$ & $2.1(0.47)$ & \\
\hline Blood Loss (ml) & & & 0.9628 \\
\hline $\mathrm{N}$ & 145 & 66 & \\
\hline Mean (SD) & $47.7(46.75)$ & $48.1(55.21)$ & \\
\hline Operative Time (Hours) & & & 0.0572 \\
\hline $\mathrm{N}$ & 179 & 81 & \\
\hline Mean (SD) & $1.5(0.64)$ & $1.3(0.63)$ & \\
\hline
\end{tabular}

* Duration of hospitalization is defined as [Date of Discharge - Date of Surgery +1]

** Using unpaired t-test to make comparison across treatments

\section{Adverse Events}

Adverse events were collected for all patients in the safety population (Table 4). Neither adverse events (AEs) in general nor those AEs deemed to be serious adverse events (SAEs) were more prevalent in the TDR group than the ACDF group. No unanticipated adverse device effects were reported in either treatment group. Eight AEs classified as related to the study device occurred in 7 out of 179 (3.9\%) TDR patients. These events were: Spinal ligament ossification (1), neck pain (4 with 1 subject reporting 2 
occurrences), muscle spasms (1), radiculopathy (1), and a case of subsidence that was not verified radiographically (this was reported by the investigator, but not verified by the independent radiograph reviewer), (1). In comparison, there were 7 AEs in 6 out of 81 (7.4\%) ACDF patients that were assessed to be related to the study device: medical device complication (3), radiculopathy (1), neck pain (2), and misplaced screw coded as medical device complication (1).

Table 4. All Treatment Emergent Adverse Events through 24 Months in US IDE Study All Study Subjects.

\begin{tabular}{|c|c|c|c|c|}
\hline \multirow[b]{2}{*}{ Complication } & \multicolumn{2}{|l|}{ Mobi-C } & \multicolumn{2}{|l|}{ ACDF } \\
\hline & $\begin{array}{l}\text { \#Patients } \\
\text { (\% of 179) }\end{array}$ & $\begin{array}{l}\text { Total } \\
\text { Events }\end{array}$ & $\begin{array}{l}\text { \#Patients } \\
\text { (\% of 81) }\end{array}$ & $\begin{array}{l}\text { Total } \\
\text { Events }\end{array}$ \\
\hline All Adverse Events ${ }^{1}$ & $170(95.0 \%)$ & 1229 & $75(92.6 \%)$ & 688 \\
\hline Anatomy/Technical Difficulty & $11(6.1 \%)$ & 12 & $2(2.5 \%)$ & 4 \\
\hline Cervical -Study Surgery & $4(2.2 \%)$ & 4 & $2(2.5 \%)$ & 3 \\
\hline Cervical - Non Study Surgery & $5(2.8 \%)$ & 6 & $1(1.2 \%)$ & 1 \\
\hline Non-Cervical & $2(1.1 \%)$ & 2 & $0(0.0 \%)$ & 0 \\
\hline Cancer & $4(2.2 \%)$ & 5 & $1(1.2 \%)$ & 2 \\
\hline Cardiovascular & $20(11.2 \%)$ & 26 & $10(12.3 \%)$ & 10 \\
\hline Death & 0 & 0 & 0 & 0 \\
\hline Dysphagia/Dysphonia & $20(11.2 \%)$ & 26 & $17(21.0 \%)$ & 20 \\
\hline Dysphagia & $19(10.6 \%)$ & 22 & $15(18.5 \%)$ & 17 \\
\hline Dysphonia & $3(1.7 \%)$ & 4 & $3(3.7 \%)$ & 3 \\
\hline Gastrointestinal & $39(21.8 \%)$ & 60 & $15(18.5 \%)$ & 37 \\
\hline Heterotopic Ossification & $9(5.0 \%)$ & 10 & $4(4.9 \%)$ & 4 \\
\hline Cervical - Index Level & $5(2.8 \%)$ & 5 & $0(0.0 \%)$ & 0 \\
\hline Cervical - Adjacent Level & $1(0.6 \%)$ & 1 & $1(1.2 \%)$ & 1 \\
\hline Non Cervical & $4(2.2 \%)$ & 4 & $3(3.7 \%)$ & 3 \\
\hline Infection & $33(18.4 \%)$ & 51 & $20(24.7 \%)$ & 28 \\
\hline Superficial Wound - Cervical & $6(3.4 \%)$ & 7 & $1(1.2 \%)$ & 1 \\
\hline Deep Wound - Cervical & 0 & 0 & 0 & 0 \\
\hline Other Wound - Non Study Surgery & $1(0.6 \%)$ & 1 & $3(3.7 \%)$ & 3 \\
\hline Systemic & $8(4.5 \%)$ & 9 & $2(2.5 \%)$ & 3 \\
\hline Local & $20(11.2 \%)$ & 34 & $18(22.2 \%)$ & 21 \\
\hline Malpositioned Implant & $2(1.1 \%)$ & 2 & $1(1.2 \%)$ & 1 \\
\hline Neck and/or Arm Pain & $102(57.0 \%)$ & 212 & $47(58.0 \%)$ & 98 \\
\hline
\end{tabular}




\begin{tabular}{|c|c|c|c|c|c|}
\hline \multirow[b]{2}{*}{ Complication } & \multicolumn{2}{|l|}{ Mobi-C } & \multicolumn{2}{|l|}{ ACDF } & \\
\hline & $\begin{array}{l}\text { \#Patients } \\
\text { (\% of 179) }\end{array}$ & $\begin{array}{l}\text { Total } \\
\text { Events }\end{array}$ & $\begin{array}{l}\text { \#Patients } \\
\text { (\% of 81) }\end{array}$ & $\begin{array}{l}\text { Total } \\
\text { Events }\end{array}$ & \\
\hline Neck Pain & $74(41.3 \%)$ & 123 & $37(45.7 \%)$ & 56 & \\
\hline Arm Pain & $46(25.7 \%)$ & 76 & $20(24.7) \%$ & 25 & \\
\hline Neck And Arm Pain & $9(5.0 \%)$ & 13 & $7(8.6 \%)$ & 17 & \\
\hline Neurological & $121(67.6 \%)$ & 401 & $52(64.2 \%)$ & 215 & \\
\hline Upper Extremity - Sensory & $67(37.4 \%)$ & 175 & $32(39.5 \%)$ & 126 & \\
\hline Upper Extremity - Motor & $26(14.5 \%)$ & 43 & $15(18.5 \%)$ & 20 & \\
\hline Upper Extremity - Reflex & $18(10.1 \%)$ & 44 & $7(8.6 \%)$ & 20 & \\
\hline Lower Extremity - Sensory & $11(6.1 \%)$ & 22 & $2(2.5 \%)$ & 3 & \\
\hline Lower Extremity - Motor & $6(3.4 \%)$ & 9 & $4(4.9 \%)$ & 4 & \\
\hline Lower Extremity - Reflex & $0(0.0 \%)$ & 0 & $1(1.2 \%)$ & 1 & \\
\hline Upper \& Lower Extremity - Sensory & $1(0.6 \%)$ & 1 & $1(1.2 \%)$ & 1 & \\
\hline Upper \& Lower Extremity - Motor & 0 & 0 & 0 & 0 & \\
\hline Upper \& Lower Extremity - Reflex & 0 & 0 & 0 & 0 & \\
\hline Neck & $41(22.9 \%)$ & 51 & $21(25.9 \%)$ & 21 & \\
\hline Back & $7(3.9 \%)$ & 8 & $2(2.5 \%)$ & 2 & \\
\hline Spinal Cord Disturbance & 0 & 0 & 0 & 0 & \\
\hline Gait Disturbance & $1(0.6 \%)$ & 1 & $1(1.2 \%)$ & 1 & \\
\hline Non Specific & $6(3.4 \%)$ & 6 & $1(1.2 \%)$ & 1 & \\
\hline Other* & $35(19.6 \%)$ & 41 & $8(9.9 \%)$ & 15 & \\
\hline Non-Union & $0(0.0 \%)$ & 0 & $4(4.9 \%)$ & 4 & \\
\hline Other** & $77(43.0 \%)$ & 114 & $33(40.7 \%)$ & 66 & \\
\hline Other Pain & $102(57.0 \%)$ & 226 & $47(58.0 \%)$ & 144 & \\
\hline Shoulder & $39(21.8 \%)$ & 55 & $21(25.9 \%)$ & 31 & \\
\hline Back & $44(24.6 \%)$ & 50 & $18(22.2 \%)$ & 30 & \\
\hline Torso & $5(2.8 \%)$ & 7 & $3(3.7 \%)$ & 4 & \\
\hline Lower Extremity & $26(14.5 \%)$ & 40 & $12(14.8 \%)$ & 29 & \\
\hline Headache & $45(25.1 \%)$ & 58 & $26(32.1 \%)$ & 41 & \\
\hline Other*** & $15(8.4 \%)$ & 16 & $8(9.9 \%)$ & 9 & \\
\hline Respiratory & $6(3.4 \%)$ & 6 & $6(7.4 \%)$ & 8 & \\
\hline Spinal Disorder & $6(3.4 \%)$ & 7 & $10(12.3 \%)$ & 12 & \\
\hline Cervical - Study Surgery & $1(0.6 \%)$ & 1 & $2(2.5 \%)$ & 2 & \\
\hline
\end{tabular}

Downloaded from http://ijssurgery.com/ by guest on April 26, 2023 


\begin{tabular}{|c|c|c|c|c|}
\hline \multirow[b]{2}{*}{ Complication } & \multicolumn{2}{|l|}{ Mobi-C } & \multicolumn{2}{|l|}{ ACDF } \\
\hline & $\begin{array}{l}\text { \#Patients } \\
\text { (\% of 179) }\end{array}$ & $\begin{array}{l}\text { Total } \\
\text { Events }\end{array}$ & $\begin{array}{l}\text { \#Patients } \\
\text { (\% of 81) }\end{array}$ & $\begin{array}{l}\text { Total } \\
\text { Events }\end{array}$ \\
\hline Cervical - Non Study Surgery & $5(2.8 \%)$ & 6 & $3(3.7 \%)$ & 3 \\
\hline Non Cervical & $0(0.0 \%)$ & 0 & $5(6.2 \%)$ & 7 \\
\hline Trauma & $47(26.3 \%)$ & 70 & $20(24.7 \%)$ & 38 \\
\hline Upper Extremity Nerve Entrapment & $8(4.5 \%)$ & 9 & $4(4.9 \%)$ & 5 \\
\hline Urogenital & $9(5.0 \%)$ & 11 & $9(11.1 \%)$ & 12 \\
\hline Vascular Intraop & $1(0.6 \%)$ & 1 & $0(0.0 \%)$ & 0 \\
\hline Wound Issue - Non-Infection & $1(0.6 \%)$ & 1 & $3(3.7 \%)$ & 3 \\
\hline Hematoma & $1(0.6 \%)$ & 1 & $3(3.7 \%)$ & 3 \\
\hline Hematoma Evacuation & 0 & 0 & 0 & 0 \\
\hline CSF Leakage & 0 & 0 & 0 & 0 \\
\hline
\end{tabular}

$\mathrm{M}=$ All Mobi-C Subjects; F = All ACDF Subjects

${ }^{1}$ Sum of all treatment emergent adverse events experienced in the study for each treatment group.

*Neurological Other includes Neurological events not appropriately defined elsewhere in the Neurological category. This includes amnesia, convulsion, facial neurologic events (dysaesthesia, hypoaesthesia), unexplained loss of consciousness, 'other' nerve compression, Parkinson's disease, and stroke.

**Other includes events not appropriately defined elsewhere. This includes adverse drug reactions, allergies, anemia, anxiety, arthritis, attention deficit disorder, benign neoplasm, blood \& lymphatic system disorders, complications from other medical procedures, congenital defects, dehydration, dermatitis, diabetes, dizziness, ear/eye disorders, endocrine disorders, fatigue, feeling hot, fever, gout, high/low cholesterol, immune system disorders, injury/poisoning, lupus, menopause, miscarriage, muscle atrophy, nutritional disorders, obesity, osteoarthritis, osteoporosis, other inflammation, other medical procedures, plantar fasciitis, polyps, pregnancy, psychiatric disorders, rotator cuff syndrome, skin disorders, sinus infection, social issues, sleep disorders, swelling, tendonitis, thyroid conditions, vascular disorders, and weight gain/loss.

***Other Pain Other includes events not appropriately defined elsewhere. This includes facial pain, fibromyalgia, muscle soreness, chronic pain, nerve pain and arthritis.

\section{Clinical Outcomes}

All clinical outcomes discussed in this section describe results from the ITT population of patients.

\section{NDI}

Baseline NDI scores for both treatment groups were not significantly different (54.0 for TDR and 54.1 for ACDF). Patients in both groups experienced significant improvement in NDI scores from baseline at all follow-up time points (Figure 5). The mean 
improvement in NDI from baseline was greater in the TDR group than the ACDF group at all time points and this difference was statistically significant at 6 weeks ( $p=0.0141)$ and 3 months $(p=0.0026)$.

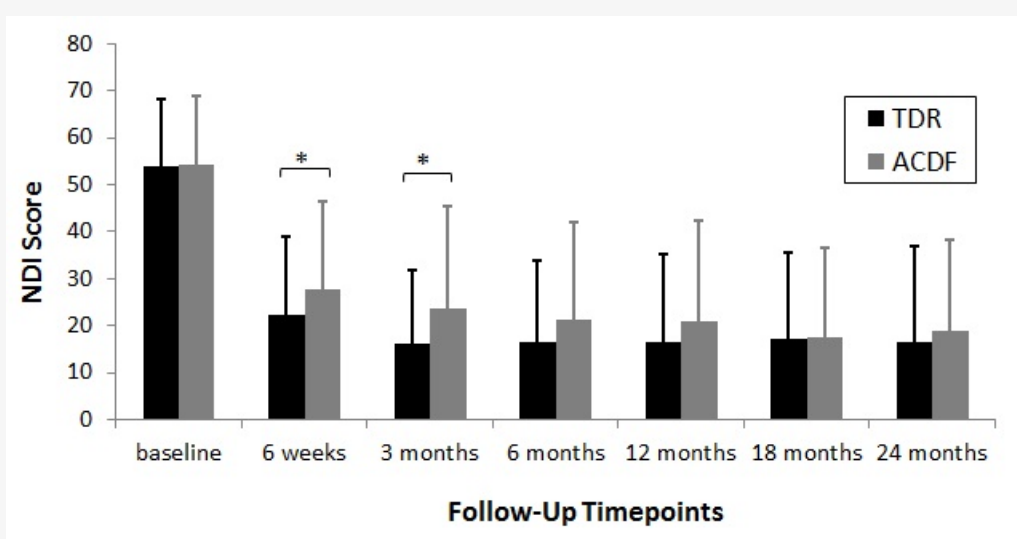

Fig. 5. Mean NDI Score by Time point. NDI scores were collected at each visit. Error bars represent standard deviations. NDI scores for both treatment groups were significantly different from baseline at all time points $(\mathrm{p}<0.05) *$ Denotes significant difference determined using unpaired t-test to compare the change from baseline between the two treatments $(\mathrm{p}<0.05)$.

In this study NDI success was defined as improvement of at least 30 points for patients with baseline NDI $\geq 60$ or improvement of at least $50 \%$ of baseline score for patients with baseline NDI $<60$. NDI success rates were slightly higher in the TDR group (79.4\%) than in the ACDF group (77.1\%).

\section{Subsequent Surgical Interventions}

Study failures by subsequent surgical interventions were defined as removal, revision, supplemental fixation, or reoperation of the implanted device and/or at the index level. Within 24 months, these procedures were performed for only two patients $(1.2 \%)$ in the TDR group and five patients $(6.2 \%)$ in the ACDF group. Implant removal was required in both groups: one patient in the TDR group (0.6\%) and three patients in the ACDF group (3.7\%). The removals performed on patients in the ACDF group were performed for "misplaced screw" and 2 instances of "failure to fuse." The one removal in the TDR group was the result of unresolved radiculopathy. Supplemental fixation was required for two patients in the ACDF group (2.5\%) and no patients in the TDR group. Both supplemental fixations were performed for pseudoarthrosis and involved the addition of posterior instrumentation at the treated level. Reoperation was required only for one patient in the TDR group (0.6\%) and no patients in the ACDF group. The TDR reoperation was performed for "right sided radiculopathies." Overall device success (defined as absence of study failure by subsequent surgical interventions) was achieved by 162 patients in the TDR group (98.8\%) and 76 patients in the ACDF group (93.8\%). 


\section{Neck and Arm Pain (VAS)}

VAS assessments were recorded for the intensity of both neck and arm pain. Neck and arm pain decreased significantly both groups at all time points when compared to baseline $(p<0.001$; Figure 6$)$. The mean change in VAS neck pain score from baseline to followup visit was greater for the TDR group than for the ACDF group at every follow-up time point, however the difference was statistically significant only at the 6 week visit $(p=$ 0.0072). Mean neck pain improvement at 24 months was similar between the two groups (17.34 for TDR; 19.36 for ACDF). A similar trend was seen for arm pain scores: mean score change from baseline to follow-up visit was greater for the TDR group than the ACDF group at each visit and mean arm pain scores at 24 months were similar between the two groups (13.6 for TDR; 13.5 for ACDF), when analyzing the arm with the worst score at baseline.

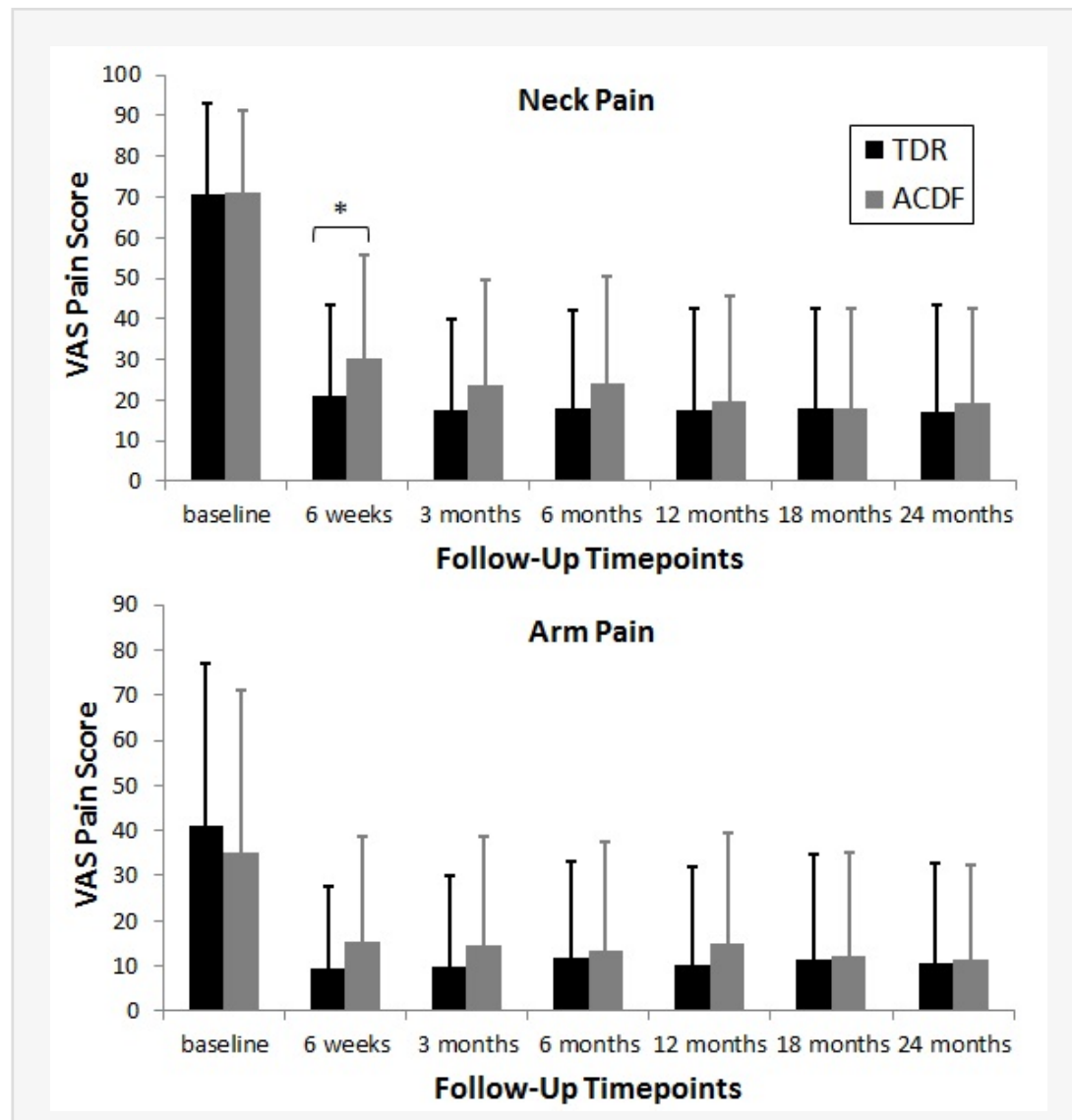

Fig. 6. Mean VAS scores by Time point. VAS pain scores were collected at each follow-up visit. Error bars represent standard deviations. VAS scores for both treatment groups were significantly different from baseline at all time points $(\mathrm{p}<0.05) *$ Denotes significant difference determined using unpaired t-test to compare the change from baseline between the two treatments $(\mathrm{p}<0.05)$.

\section{Neurologic Success}

Neurological success was defined as maintenance or improvement in each of the neurological evaluations including motor assessments (muscle strength), reflex assessments, and sensory deficit assessments (pin prick and light touch). Failure of any 
one of the three neurological assessments was deemed a neurological failure. At 24

months, only $1.9 \%$ of TDR patients and $2.9 \%$ of ACDF patients were deemed

neurological failures.

\section{Radiographic Findings}

Plain films were used to assess subsidence, migration, significant radiolucency, range of motion of the treated segment, and adjacent segment degeneration. There were no cases of migration, subsidence, or significant radiolucency in either group at the 24 month visit.

At the 24 month follow-up visit 6 patients in the TDR group were determined to show evidence of spontaneous fusion at the treated level; resulting in $97.0 \%$ radiographic success rate. The 6 patients in the TDR group that were determined to be radiographic failures had an average range of motion of $0.67^{\circ}$ at the treated level and showed evidence of bridging bone across the disc space. One additional patient in the TDR group showed bridging bone across the disc space, but was not determined to be a radiographic failure because the patient still maintained flexion-extension range of motion of $6.4^{\circ}$. At 24 months this patient was determined to be an overall study success. There were no other instances of bridging bone in the TDR cohort.

At the 24 month follow-up visit, 8 patients in the ACDF group were categorized as a radiographic failure, resulting in a radiographic success rate in this group of $89.3 \%$. Six of the 8 patients in the ACDF group that were determined to be radiographic failures had more than $2^{\circ}$ range of motion at the treated level despite each of these patients demonstrating bridging bone across the disc space. Two of the 8 patients showed less than $2^{\circ}$ range of motion but there was no evidence of bridging bone. There were no instances of radiolucent lines at more than $50 \%$ of the graft vertebral interfaces in the ACDF group.

The ACDF group showed restricted ROM at all post-operative study visits and the mean values at 24 months were less than $1^{\circ}$ for both left/right lateral and flexion/extension bending. The mean values for TDR patients were higher than baseline at the week 6 visit and by the 24 month visit, were $10.8^{\circ}\left( \pm 6.5^{\circ}\right)$ for flexion/extension bending and $5.4^{\circ}$ $\left( \pm 3.1^{\circ}\right)$ for left/right lateral bending (Figure 7). 


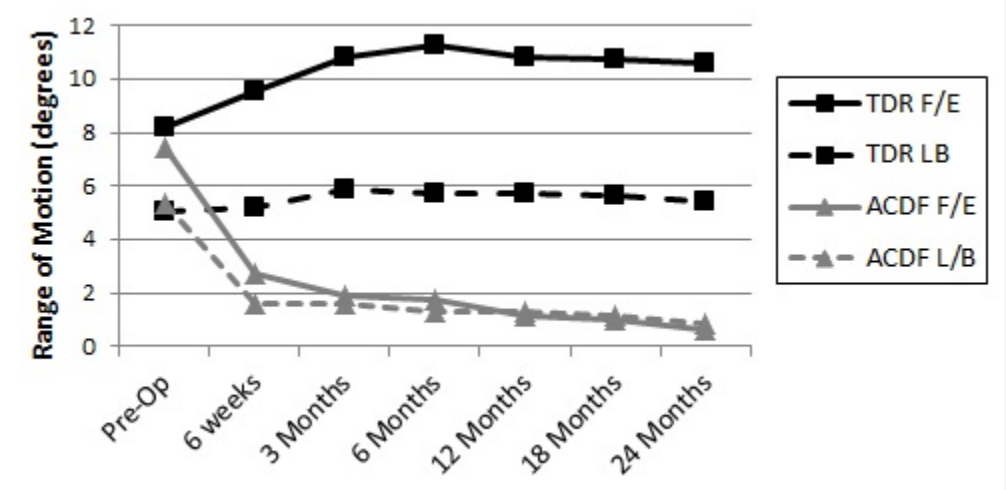

Fig. 7. Range of Motion by Time point. Line graph demonstrating range of motion at the treated segment in Flexion/Extension (F/E) and Right/Left Lateral Bending (LB)

At all time points, including baseline, radiographic evidence of disc degeneration (Kellgren-Lawrence score greater than 0 ) was noted more frequently at the supra-adjacent segment than infra-adjacent segment. At 12 months $93.8 \%$ of patients in the TDR group and $91.3 \%$ of patients in the ACDF group had no change in disc degeneration score for the superior segment. At 24 months, the percentage of patients who had no change in score for this segment decreased in both groups to $85.4 \%$ for the TDR group and $75.0 \%$ for ACDF. At neither time point was the difference between groups statistically significant.

At the inferior adjacent segment, the percentage of patients with no change in disc degeneration score from baseline to 12 months was $98.5 \%$ for the TDR group and $87.5 \%$ for the ACDF group. At 24 months these percentages decreased to $92.3 \%$ for the TDR group and $79.0 \%$ for ACDF. These differences were statistically significant at both time points.

\section{Quality of life (SF-12)}

Mean physical component summary (PCS) and mental component summary (MSC) scores were higher than baseline for all time points. Both the PCS and MCS questionnaires are scored out of 100 total points. At 24 months, TDR patients had a mean PCS score of 48.3 with a mean change from baseline of +15.7 and ACDF patients had a mean PCS score of 46.5 with a mean change from baseline of +13.0 . At this same timepoint, TDR patients had a mean MCS score of 51.0 with a mean change from baseline of +8.5 and ACDF patients had a mean MCS score of 49.2, with a mean change from baseline of +7.2. The mean change in score for both PCS and MCS was higher in the TDR group than the ACDF group at all time points, however the difference between the TDR and ACDF groups was only statistically significant for the PCS score in favor of TDR at the 6 months follow-up visit $(p$ value $=0.0367)($ Figure 8$)$. 


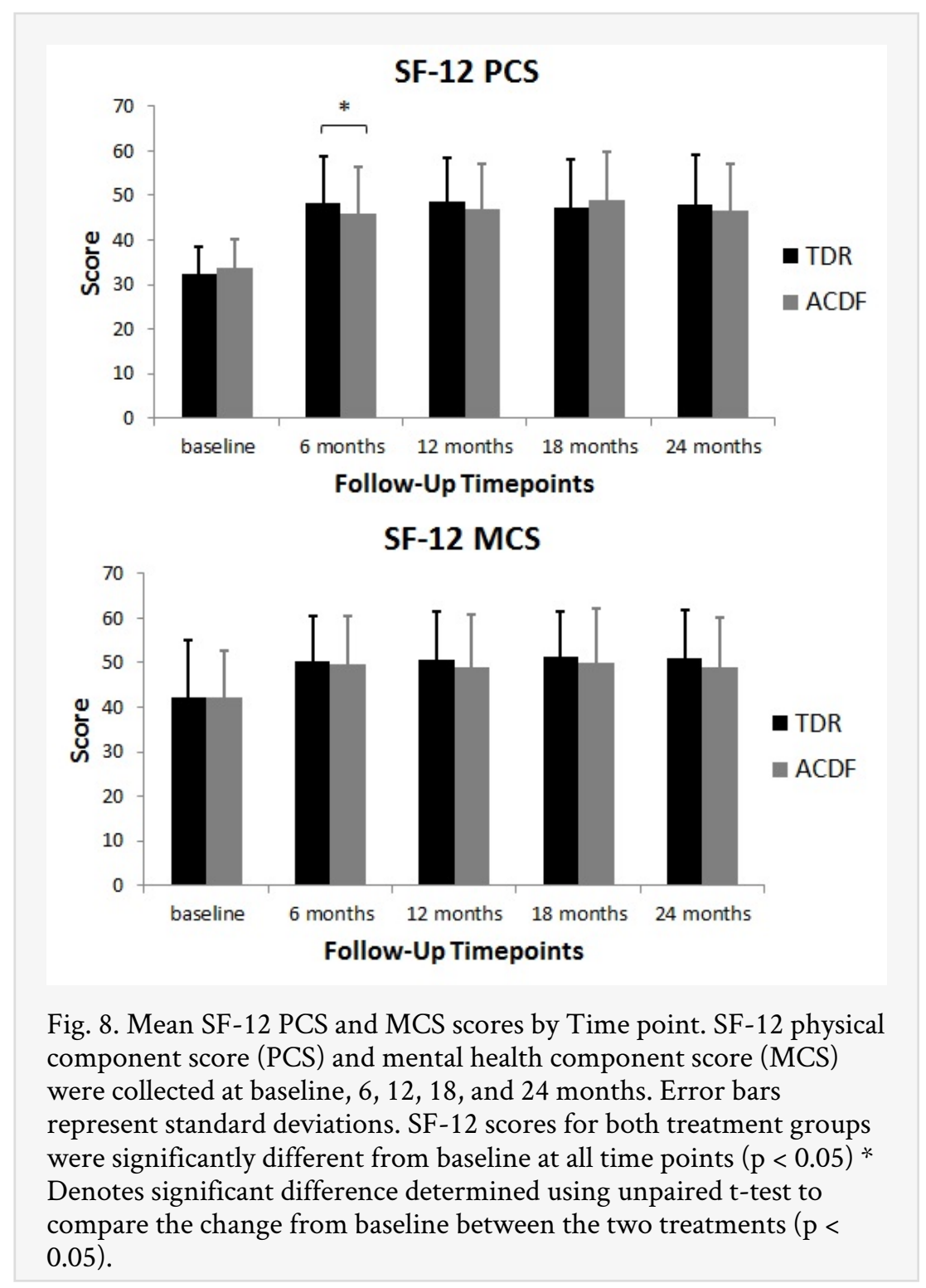

\section{Patient satisfaction}

Patient satisfaction with surgical treatment, as assessed by questionnaires, was high in both treatment groups. More than $95 \%$ of both TDR patients and ACDF patients answered that they were "very satisfied" or "somewhat satisfied" and more than $93 \%$ of both groups responded that they would make a surgery recommendation of "definitely yes" or "probably yes".

\section{Time to return to work}

TDR patients returned to work in a mean of 30.1 days ( \pm 24.6 days), with a median of 21.0 days. The patients in the ACDF group had a similar slightly higher mean time to return to work of 36.8 days ( \pm 40.3 days), with a median of 22.0 days. 


\section{Discussion}

The results of this trial demonstrate that TDR is non-inferior to ACDF when analyzed by the composite primary endpoint $(\mathrm{p}=0.002)$. The primary endpoint assessed individual patient success as demonstrated by functional improvement (NDI), no need for subsequent surgical intervention (removal, revision, supplemental fixation, and reoperation), and the absence of study defined major complications. A non-inferiority result, measured by the primary composite endpoint, was not surprising as the fundamentals of these two surgical procedures are very similar. Both surgeries involve the same surgical approach, a thorough discectomy, nerve decompression, disc height restoration, and placement of a device in the disc space. With disc height restored and nerve impingement eliminated, the authors of this study anticipated similar improvements in both groups in terms of decreased neck and arm pain, increased muscle strength, and elimination of abnormal sensations (hyperesthesia or hypoesthesia) and/or abnormal reflexes. Indeed, patients in the both the TDR group and the ACDF group showed marked improvement after surgery reporting decreased neck and arm pain, low rates of neurologic deterioration, improvement in quality of life, high patient satisfaction, and low rates of study defined major complications.

However, TDR demonstrated some advantages over ACDF particularly when clinical outcomes are analyzed in the short term. Notably, TDR achieved a higher patient success rate by 6 months than ACDF achieved by 24 months for the primary composite endpoint. This higher success rate for TDR at 6 months compared to ACDF at 24 months was still present when radiographic complications were excluded as a reason for overall study failure. Clinical outcome measures also indicated that patients in the TDR group generally achieved positive results earlier than the patients in the ACDF group. There were statistically significant differences in favor of TDR observed for mean NDI improvement at 6 weeks and 3 months, mean neck pain VAS improvements at 6 weeks, and mean SF-12 PCS improvement at 6 months.

Furthermore, while both ACDF and TDR treatment achieve restoration or maintenance of the disc height and anterior neural decompression, another advantage of TDR over ACDF is thought to be preservation of motion at the treated segment. Range of motion results demonstrate that, as expected, the patients in the ACDF group showed restricted ROM at all post-operative study visits. The mean values at Month 24 were less than $1^{\circ}$ for both left/right lateral and flexion/extension bending. However, the TDR group patients on average maintained or increased ROM post-operatively by the 6 week visit and this result is consistent through 24 month visit. This maintenance or increase in ROM occurred in both flexion/extension and left/right lateral bending. It has been postulated that the restriction of motion at the treated segment with an ACDF is one factor contributing to the development of adjacent level disease. ${ }^{32,33}$ In this study fewer TDR patients had deterioration of the adjacent segments during the course of the study and this difference was statistically significant for the inferior adjacent segment. These results suggest that the preservation of motion by the TDR may play a role in reducing the rate of deterioration of the adjacent segments, in particular the inferior adjacent segment. 
In order to ensure consistent treatment between TDR and ACDF patients, the protocol disallowed the use of NSAIDs from 1 week preoperatively and instructed physicians not to prescribe NSAIDs prophylactically postoperative in either group unless intended to treat diagnosed heterotopic ossification. The prophylactic use of NSAIDs may have benefitted TDR patients by reducing the likelihood of heterotopic ossification, but could have been detrimental to ACDF patients by delaying fusion. The use of NSAIDs prophylactically in the prevention of heterotopic ossification formation after hip arthroplasty is well documented. ${ }^{34,35,36} 97.0 \%$ of TDR patients achieved radiographic success; leaving only $3.0 \%$ defined as radiographic failures (the unwanted spontaneous fusion at the treatment site) at 24 months. This is compared to $10.7 \%$ of the ACDF patients that were defined as radiographic failures (the failure to fuse at the treated level) at 24 months. Although a 3.0\% radiographic failure rate is relatively low, it is possible that had NSAIDS been used prophylactically for the TDR group the radiographic failure rate may have been even lower.

The results of this study are similar to those reported for FDA IDE trials evaluating other cervical TDR devices with 2-year follow-up comparing the results to ACDF using allograft and an anterior plate. ${ }^{16,17,18,37}$ These prospective, randomized trials have produced consistent results finding TDR to be non-inferior to ACDF with additional post hoc analyses finding TDR to be superior on some measures. In all studies, significant improvement was seen at early follow-up and maintained throughout 24-month follow-up in both treatment groups. Unfortunately, some of the definitions and assessments used in the studies varied, making data pooling and/or direct comparisons between studies potentially unreliable.

\section{Conclusions}

This prospective, randomized trial comparing TDR to fusion showed that the TDR is a viable alternative to $\mathrm{ACDF}$, with some advantages in early recovery and potentially some advantage to reduce adjacent segment degeneration. These results are similar to previously published TDR trials in that overall success rates of TDR are shown to be noninferior to overall success rates of ACDF, and patients in the TDR group tended to see earlier success in terms of both overall study success and clinical outcomes. ${ }^{16,17,18}$ The robustness of the non-inferiority of TDR was confirmed by analysis of overall success rates in both groups while ignoring radiographic complications, as radiographic complications may have limited clinical relevance. ${ }^{11}$ TDR was also associated with reduced adjacent segment deterioration evident on radiographs compared to fusion, however the clinical implication of the reduced adjacent segment degeneration may require longer follow-up. This study demonstrated that TDR preserved physiologic motion, while providing clinical benefits consistent with ACDF. The authors believe that the current study provides evidence that TDR with Mobi-C Artificial Cervical Disc is as safe and clinically effective as ACDF at 2-years follow-up, and that TDR with this device has potential benefits over ACDF.

\section{References}

1. Denaro V, Papalia R, Denaro L, et al. Cervical spinal disc replacement. J Bone Joint Surg Br 2009;91:713-9. 
2. Denaro V, Di Martino A. Cervical spine surgery: an historical perspective. Clin Orthop Relat Res 2011;469:639-48.

3. Mummaneni PV, Haid RW. The future in the care of the cervical spine: interbody fusion and arthroplasty. Invited submission from the Joint Section Meeting on Disorders of the Spine and Peripheral Nerves, March 2004. J Neurosurg Spine 2004;1:155-9.

4. Brodke DS, Zdeblick T. Modified Smith-Robinson procedure for anterior cervical discectomy and fusion. Spine 1992;17(suppl):427-30.

5. Bohlman HH, Emery SE, Goodfellow DB, Jones PK. Robinson anterior cervical discectomy and arthrodesis for cervical radiculopathy. Long-term follow-up of one hundred and twenty-two patients. J Bone Joint Surg Am 1993;75:1298-307.

6. Boakye M, Mummaneni PV, Garrett M, et al. Anterior cervical discectomy and fusion involving a polyetheretherketone spacer and bone morphogenetic protein. J Neurosurg Spine 2005;2:521-5.

7. Gore DR, Sepic SB. Anterior cervical fusion for degenerated or protruded discs. A review of one hundred forty-six patients. Spine 1984;9:667-71.

8. Brown JA, Havel P, Ebraheim N, et al. Cervical stabilization by plate and bone fusion. Spine 1988;13:236-40.

9. Nabhan A, Ahlhelm F, Shariat K, et al. The ProDisc-C prosthesis: clinical and radiological experience 1 year after surgery. Spine 2007;32:1935-41.

10. Hilibrand AS, Robbins M. Adjacent segment degeneration and adjacent segment disease: the consequences of spinal fusion? Spine J 2004;4:190S-4S.

11. Nunley PD, Jawahar A, Kerr EJ, 3rd, et al. Choice of plate may affect outcomes for single versus multilevel ACDF: results of a prospective randomized single-blind trial. Spine J 2009;9:121-7.

12. Zindrick M, Harris MB, Humphreys SC, et al. Cervical disc arthroplasty. J Am Acad Orthop Surg 2010;18:631-7

13. Cummins BH, Robertson JT, Gill SS. Surgical experience with an implanted artificial cervical joint. J Neurosurg 1998;88:943-8.

14. Cepoiu-Martin M, Faris P, Lorenzetti D, et al. Artificial cervical disc arthroplasty (ACDA): a systematic review. Spine 2011;36:E1623-E33.

15. Rhee JM. Cervical arthroplasty: a success, failure, or both? Spine J 2010;10:731-2.

16. Heller JG, Sasso RC, Papadopoulos SM, et al. Comparison of BRYAN cervical disc arthroplasty with anterior cervical decompression and fusion: clinical and radiographic results of a randomized, controlled, clinical trial. Spine 2009;34:101-7.

17. Mummaneni PV, Burkus JK, Haid RW, et al. Clinical and radiographic analysis of cervical disc arthroplasty compared with allograft fusion: a randomized controlled clinical trial. J Neurosurg Spine 2007;6:198-209.

18. Murrey D, Janssen M, Delamarter R, et al. Results of the prospective, randomized, controlled multicenter Food and Drug Administration investigational device exemption study of the ProDisc-C total disc replacement versus anterior discectomy and fusion for the treatment of 1-level symptomatic cervical disc disease. Spine J 2009;9:275-86.

19. Burkus JK, Haid RW, Traynelis VC, Mummaneni PV. Long-term clinical and radiographic outcomes of cervical disc replacement with the Prestige disc: results from a prospective randomized controlled clinical trial. J Neurosurg Spine 2010;13:308-18. 
20. Quan GM, Vital JM, Hansen S, Pointillart V. Eight-year clinical and radiological follow-up of the Bryan cervical disc arthroplasty. Spine 2011;36:639-46.

21. Zigler JE, Delamarter R, Murrey D, et al. ProDisc-C and anterior cervical discectomy and fusion as surgical treatment for single-level cervical symptomatic degenerative disc disease: five-year results of a Food and Drug Administration study. Spine 2013;38:203-9.

22. Beaurain J, Bernard $\mathrm{P}$, Dufour $\mathrm{T}$, et al. Intermediate clinical and radiological results of cervical TDR (Mobi-C) with up to 2 years of follow-up. Eur Spine J 2009;18:841-50.

23. Huppert J, Beaurain J, Steib JP, et al. Comparison between single- and multi-level patients: clinical and radiological outcomes 2 years after cervical disc replacement. Eur Spine J 2011;20:1417-26.

24. Nunley PD, Jawahar A, Cavanaugh DA, et al. Symptomatic adjacent segment disease after cervical total disc replacement: re-examining the clinical and radiological evidence with established criteria. Spine J 2013;13:5-12.

25. Coric D, Nunley PD, Guyer RD, et al. Prospective, randomized, multicenter study of cervical arthroplasty: 269 patients from the Kineflex $\mid \mathrm{C}$ artificial disc investigational device exemption study with a minimum 2-year follow-up. J Neurosurg Spine 2011;15:348-58.

26. Blumenthal SL, Ohnmeiss DD, Guyer RD, Zigler JE. Re-operations in Cervical Total Disc Replacement Compared with Anterior Cervical Fusion: Results Compiled from Multiple Prospective FDA IDE Trials Conducted at a Single Site. Spine 2013;38:1177-82.

27. Davis RJ, Kim KD, Hisey MS, et al. Cervical total disc replacement with the Mobi-C cervical artificial disc compared with anterior discectomy and fusion for treatment of 2-level symptomatic degenerative disc disease: a prospective, randomized, controlled multicenter clinical trial. J Neurosurg Spine 2013;19:532-45.

28. Reitman CA, Hipp JA, Nguyen L, Esses SI. Changes in segmental intervertebral motion adjacent to cervical arthrodesis: a prospective study. Spine 2004;29:E221-6.

29. 29. Zhao K, Yang C, Zhao C, An KN. Assessment of non-invasive intervertebral motion measurements in the lumbar spine. J Biomech 2005;38:1943-6.

30. Kettler A, Wilke HJ. Review of existing grading systems for cervical or lumbar disc and facet joint degeneration. Eur Spine J 2006;15:705-18.

31. Kellgren JH. The University Centre for the study of chronic rheumatism. Manch Med Gaz 1962;42:4-7.

32. Dmitriev AE, Cunningham BW, Hu N, et al. Adjacent level intradiscal pressure and segmental kinematics following a cervical total disc arthroplasty: an in vitro human cadaveric model. Spine 2005;30:1165-72.

33. Kulkarni V, Rajshekhar V, Raghuram L. Accelerated spondylotic changes adjacent to the fused segment following central cervical corpectomy: magnetic resonance imaging study evidence. J Neurosurg 2004;100:2-6.

34. Fijn R, Koorevaar RT, Brouwers JR. Prevention of heterotopic ossification after total hip replacement with NSAIDs. Pharm World Sci 2003;25:138-45

35. Kjaersgaard-Andersen P, Schmidt SA. Total hip arthroplasty. The role of antiinflammatory medications in the prevention of heterotopic ossification. Clin Orthop Relat Res 1991;78-86. 
36. McMahon JS, Waddell JP, Morton J. Effect of short-course indomethacin on heterotopic bone formation after uncemented total hip arthroplasty. J Arthroplasty 1991;6:259-64.

37. Coric D, Kim PK, Clemente JD, et al. Prospective randomized study of cervical arthroplasty and anterior cervical discectomy and fusion with long-term follow-up: results in 74 patients from a single site. J Neurosurg Spine 2013;18:36-42.

\section{Corresponding author}

Michael S. Hisey, M.D.Texas Back Institute - Denton, 2817 South Mayhill Rd., Suite 100, Denton, TX 76208. mhisey@texasback.com

\section{Financial Disclosures}

Ralph Rashbaum has stock in LDR Spine. Hyun Bae is a patent holder for LDR Spine, receives royalty from LDR spine, and invests in a private fund that holds equity in LDR Spine. Michael Heisey is a patent holder for a different LDR product and is on the speaker bureau for Mobi-C training. Kee Kim is a patent holder for LDR Spine and receives royalties from LDR Spine. Pierce Nunley is a consultant for LDR Spine and receives royalty from LDR Spine. Reggie Davis is a consultant for LDR Spine. Steven Gaede has received research support for Mobi-C clinical trials from LDR Spine. Greg Hoffman is a consultant for LDR Spine and owns stock in LDR Spine. Daniel Peterson owns stock in LDR Spine.

Copyright (C) 2014 ISASS - International Society for the Advancement of Spine Surgery. To see more or order reprints or permissions, see http://ijssurgery.com. 